to cover many aspects of marine science, and waters that offer open coastal seas to sheltered estuaries. So why not base our course here? To begin with, our firstyear undergraduates do their initial field course here. They also spend all four years of their degree working on the waters in and around Southampton. Staff would be less accessible, as most would be nipping out for meetings-or home for the weekend-all of which detract from the learning experience of a field course. Students would also be disappearing off into their own established social groups rather than bonding with their new group during the off-duty periods.

Many years ago we did an exchange where we ran a field course with the University of East Anglia with some of their oceanography and meteorology students working at Southampton and some of our students working there. Academic staff from each followed their own students, but the vessels, labs, and sup- port staff were from the home university. There was limited exchange of money, running on a quid pro quo basis, and it worked well. The core courses changed in character and the exchange stopped. More recently, there was a network of European universities that ran a limited set of summer schools where students opted to undertake a course at one of the partner institutes. It was a limited experiment that unfortunately stopped when the EU funding ended.

I would like to propose a global network of summer schools-similar to those run at institutes like the Bermuda Institute of Ocean Sciences (BIOS) but on an exchange basis. Students might opt for a summer school in BIOS on tropical zone ecology, or a summer school in Svalbard on polar oceanography, in Plymouth on stratified coastal seas, or Southampton on estuaries and coastal environments. Southampton may not sound much like a field trip for one of its own students, but for a student from the University of Bergen or the University of North Carolina Wilmington, it is different enough and provides a wide range of experiences and techniques. A scheme like this would reduce costs to the home institutions, which are set up for teaching oceanography very efficiently in their home waters. Students would select an area of interest and have a chance to work with a group of young scientists from across the globe. It would need to be on a no fee basis to work efficiently, but would benefit the partners both financially and in terms of an enhanced student experience. Any takers? The only down side is I will end up back in Southampton and still never get to one of those exotic locations. My wife, who often proof reads these columns for me, is up for that. @

\section{AUTHOR}

Simon Boxall (srb2@noc.soton.ac.uk) is Associate Professor, Ocean and Earth Science, University of Southampton, National Oceanography Centre, Southampton, UK.

\title{
Vast Expanses: A History of the Oceans
}

\begin{abstract}
By Helen M. Rozwadowski, 2019, Reaktion Books Ltd., London, UK, 264 pages, ISBN: $9781780239972, \$ 25.00$ USD
\end{abstract}

Reviewed by lan Brosnan

Helen Rozwadowski's Vast Expanses: A History of the Oceans is a concise and sweeping study of the ocean and our varied, changing relationship with it. The book seeks to carve out a role for the humanities in the future and fate of the ocean by defining our historical connectedness with the ocean. It does not offer to provide a definitive history, but instead to proffer a model for writing the history of the ocean that inspires others to fuller, more inclusive works.

In her book, Dr. Rozwadowski draws together our connections to the four dimensions of the ocean, their acceleration under industrialization and globalization, and the mediating role that increasing knowledge of the ocean has played. The first three chapters are fastpaced, almost choppy, as the author works to cover a lot of ground in a short span of writing. Chapter 1 (A Long Sea Story) covers the biogeophysical history and properties of the ocean, beginning with the arrival on Earth of water bound in interstellar bodies and moving quickly to conclude with the impact of the Last Glacial Maximum on coastal communi-

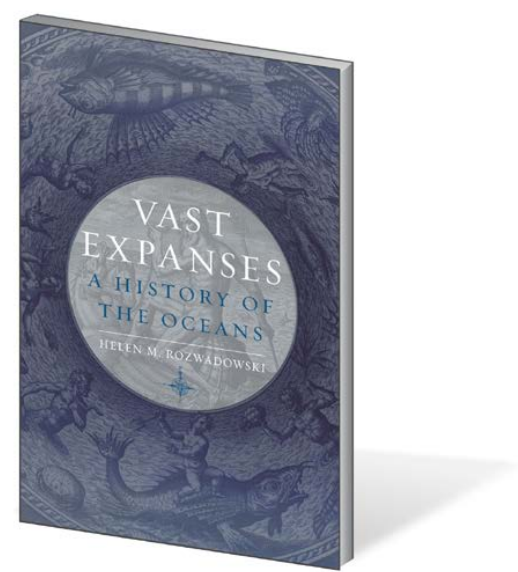

ties. Chapter 2 (Imagined Oceans) introduces the histories and relationships to the ocean of coastal cultures from around the world. Chapter 3 (Seas Connect) charts the growth of trading routes from a coastal to global scales, and accompanying impacts and changes in technology and conventions governing the use of the ocean.

All of the chapters in the book are about 30 pages long, but as the author transi- 
tions to covering narrower topics, the narrative becomes smoother. Chapter 4 (Fathoming All the Ocean) explores the discovery of the ocean below the surface, and its impacts on science, industry, and culture. Chapter 5 (Industrial Ocean) reviews the rise of industrial uses of ocean resources, particularly fisheries, and a counterintuitive change in the cultural perception of the ocean as a site of utilitarian economic and geopolitical activity to a place that is timeless, untouchable, and apart from society. Chapter 6 (Ocean Frontier) follows the characterization of the ocean as a new frontier, optimistic visions for human settlement and use of the ocean, and the realized visions of the post-war period from the 1950s to the 1970s. Chapter 7 (Accessible Ocean) explores the growing accessibility of the ocean through aquariums, films, and SCUBA, the rise of the environmental movement, and efforts to protect and preserve the ocean. The epilogue catalogs contemporary threats to the ocean and concludes with a call for the humanities to transform human understanding of the seas to one intimately linked with our history and future and set the stage for positive change.

The book is impressive in its breadth, and all but the most widely read scholars will likely uncover a few historical details that had previously escaped their attention. Writing such a broad yet concise treatise must have some drawbacks, however. First, the book passes over some important and relevant work. For example, there is no mention of Alfred Thayer Mahan, whose writing in the late 1800 s figured prominently in the recognition of sea power as a key element of the military and economic instruments of national power that underpin contemporary exploitation of the ocean. Mahanian thinking is infused in contemporary Chinese maritime strategy (Yoshihara and Holmes, 2018), and this has implications for doctrinal concepts such as freedom of the seas, as well as the future relationship between nearly $20 \%$ of the world's population and the ocean.

There are also occasional inconsistencies and missing nuance. At one point, the author lays out an argument that the 1872 Challenger expedition was not the foundation of modern oceanography, but then describes it as foundational four pages later. A more nuanced view of the Challenger expedition might give it a seminal, rather than foundational, place in oceanographic history.

Finally, although the book intends to inspire fuller studies of neglected topics in ocean history (and did give me cause to think about some aspects of ocean his- tory that would be interesting to explore), it largely covers topics that have already been well described and provides only fleeting hints of overlooked topics that may benefit from fuller study, such as extra-European influences on Hugo Grotius' Mare Liberum.

Should you, avid reader of Oceanography, read this book? On the one hand, setting out a position for the humanities in effecting positive change in our relationship with the ocean is a noble task. Dr. Rozwadowski, a professor and founder of the Maritime Studies Program at the University of Connecticut, is well placed for this task, and if you want to understand this position, you should read the book. However, the book covers nothing that is new in ocean history, and little that will not already be familiar to those for whom the ocean is a professional medium. If you find the ocean to be dynamic, historically rich, and heavily impacted by human activity, gift the book to someone who doesn't. @

\section{REFERENCE}

Yoshihara, T., and J.R. Holmes. 2018. Red Star Over the Pacific, $2^{\text {nd }}$ ed. Naval Institute Press, Annapolis, MD, 376 pp.

\section{AUTHOR}

lan Brosnan (ian.g.brosnan@nasa.gov) is a scientist at the NASA's Ames Research Center and an associate editor of Oceanography. 